\title{
The Chinese-English Lyrics Translation of See the Next Intersection from the Perspective of Skopos Theory
}

\author{
Min Peng \\ School of Foreign Languages, Yunnan University, Kunming, China \\ Email:yumipeng0310@163.com, pengmin@mail.ynu.edu.cn
}

How to cite this paper: Peng, M. (2020) The Chinese-English Lyrics Translation of See the Next Intersection from the Perspective of Skopos Theory. Open Access Library Journal, 7: e6756.

https://doi.org/10.4236/oalib.1106756

Received: August 27, 2020

Accepted: September 26, 2020

Published: September 29, 2020

Copyright $\odot 2020$ by author(s) and Open Access Library Inc.

This work is licensed under the Creative Commons Attribution International License (CC BY 4.0).

http://creativecommons.org/licenses/by/4.0/

\section{(c) (i) Open Access}

\begin{abstract}
Composed by China's most celebrated star Li Yuchun, See the Next Intersection (下个, 路口, 见) is an extraordinarily popular song. Under the three rules of the Skopos theory, this paper explores the translator's goal of integrating music and words through flexible translation techniques to achieve communication across cultural and language barriers. However, some slight flaws emerge during the process due to the translator's extreme attention to the Skopos rule. Moreover, this paper provides some enlightenment about rendering song lyrics exquisitely while considering the proper balance of the three rules.
\end{abstract}

\section{Subject Areas}

Translation Theories and Applications, Linguistics, Literature

\section{Keywords}

Skopos Theory, Lyrics Translation, See the Next Intersection

\section{Introduction}

\subsection{The Song See the Next Intersection and the Research Significance}

As one of China's most prominent stars, Li Yuchun, also known as Chris Lee, is a singer, actress, and fashion muse [1]. She garners a loyal fanbase and gains worldwide recognition due to her outstanding musical talent and personal chrisma. Composed and sung by Li Yuchun in 2009, See the Next Intersection (下个, 路口, 见) is one of her most famous songs, which become an immediate hit across the country in virtue of its brisk melody and romantic lyrics. Her ex- 
uberant imagination endows the song with an emotional story of love at a vast distance. The two commas in the title imply wealthy pauses and waits in life. Nevertheless, people may come across each other at the next intersection as long as they can transcend time [2]. The Chinese lyrics of See the Next Intersection is rendered to English by Daphne and sung by Amos. They both are members of an original music group called Ave. 6 Music Studio [3]. The English version of See the Next Intersection also enjoys high popularity among people. Furthermore, the full Chinese-English lyrics of See the Next Intersection is listed as Appendix [4] at the end of this paper.

With China's prosperous rising and thriving, more and more people increasingly turn their attention to Chinese culture. Music is the universal language of all humankind and is the easiest way for people to understand China. As an essential part of global cultural communication, music plays a crucial role in forstering cultural exchanges between China and the world. Since the music industry is gaining momentum, the translation of lyrics counts for much in art appreciation and cultural exchanges. Hence, relevant studies of lyrics translation should be brought to the forefront. This paper examines the Chinese-English lyrics translation techniques of this pop song based on the Skopos theory, aiming to illuminate the distinctive features of lyrics translation. Besides, this paper discovers a few grammar flaws possibly rendered by the translator's highest focus on integrating rhythm and melody.

\subsection{The Skopos Theory}

The Skopos theory belongs to functional theories, which rise in Germany in the 1970s-1980s, marking a move away from linguistic typologies towards a consideration of culture (Munday, 2016: p. 113) [5]. Skopos is a Greek word for "aim" or "purpose" and is introduced into translation theory in the 1970s by Hans J. Vermeer (1930-2010) as a technical term for the purpose of a translation and of the action of translating (Munday, 2016: p. 126) [5]. Apart from the term Skopos, Vermeer also uses the related words "aim", "purpose", "intention", and "function" (Nord, 2018: p. 27) [6].

The translation is a type of human action. Vermeer considers human actions as intentional, purposeful behavior that takes place in a given situation (Nord, 2018: p. 11) [6]. In 1978, he first puts forward the Skopos theory, giving three primary rules: the Skopos rule, the coherence rule, and the fidelity rule. The highest rule of a theory of translational action is the Skopos rule, which specifies that any action is determined by its purpose (Reiß \& Vermeer, 2014: p. 90) [7]. In other words, translation is determined by the prospective function or purpose of the translated text as determined by the translation initiator, which is the paramount rule among the three rules. The coherence rule states that a translation should be coherent with or acceptable in the receiver's situation. It should conform to the conventions established in the target culture for the text type in question (Nord, 2018: p. 98) [6]. However, since a translation is an offer of in- 
formation about the preceding one, it is expected to bear some relationship with the corresponding source text. Vermeer calls this relationship "intertextual coherence" or "fidelity". This is postulated as a further principle, referred to as the "fidelity rule" (Nord, 2018: p. 31) [6]. Fidelity (intertextual coherence) is considered subordinate to the coherence rule (intratextual coherence), and both are subordinate to the Skopos rule. If the Skopos requires a change of function, the standard will no longer be intertextual coherence with the source text but adequacy or appropriateness concerning the Skopos. Moreover, if the Skopos demands intratextual in coherence (as in the theater of the absurd), the standard of intratextual coherence is no longer valid (Nord, 2018: p. 31) [6].

Thus, the internal coherence of the translated text and the realization of the fidelity to the source text mainly depend on the purpose of translation.

\section{Chinese-English Lyrics Translation Strategies in See the Next Intersection under Skopos Theory}

\subsection{Skopos Rule}

The top-ranking rule for any translation is the "Skopos rule", which says that its Skopos determines a translational action, that is, "the end justifies the means" (Nord, 2018: p. 28) [6]. According to Vermeer, the Skopos rule stipulates that each text is produced for a given purpose and shall serve this purpose (Nord, 2018: p. 28) [6]. As the most popular song, each Chinese line of See the Next Intersection rhymes, adding to the difficulty of its translation. Thus, the purpose of song lyrics translation lies in its integration of music and words, i.e. singability.

\subsubsection{Omission}

The omission is commonly used in the translation. A proper omission is to make the translated version more explicit and expressive. Specifically, translators often omit some dispensable words, such as articles (a, an, the), prepositions (in, on, with, for, to), specific pronouns (it, he, she), and more, for rhyme and melody (Li \& Duan, 2016: p. 40) [8].

\section{Example 1}

Source Text: 收音机你听几点几

Translated Text: Radio, which channel you are (are you) listening (to)?

Analysis: By grammatical rules, the preposition "to" shall not be omitted. However, the omission here is to form rhymes with the final syllable of "arrive in" and "rainy" in its front lines. Despite its omission, the text does not cause mix-understanding or confusion among listeners. Hence, the omission is workable and feasible, but there is still room for improvement in the translation to make it acceptable in grammar. Moreover, when it comes to lyrics translation, translators tend to give more priority to their rhyme and melody than grammar. Even so, it does not mean grammar can be sacrificed at a manageable cost.

Besides, the translated text bears some tiny flaws. The $\mathrm{WH}$-words are also called interrogatives. They are used for $\mathrm{WH}$-questions and can be determiners, 
adverbs, or pronouns. As determiners, "which" is used to ask questions and make the sentence take the interrogative word order except for an object clause [9]. However, the translator does not follow this anyhow. Since omitting "to" is for rhyme and melody's purpose, the minor grammatical problem it brings about is understandable. Although lyrics translation is not about lexically precise, the WH-question's improper use may ascribe to the translator's pretermission.

\section{Example 2}

Source Text: 我早茶月光酒在你头发

Translated Text: Sprinkle the silver moon dust on your hair

Analysis: The source text indicates there are different time zones between the two people or maybe lovers. One is having morning tea, while night is descending in the other one's place. As morning tea is a typical Chinese custom and the time difference is mentioned ahead, the translator omits the translation of “早 茶” for rhythm and melody. Instead, she emphasizes the exotic image of the "sliver moon", echoing to such Western songs as Close to You and Moondust.

Example 3

Source Text: 东京下雨 淋湿巴黎

Translated Text: Tokyo's rainy (day), Paris' rainy (day)

Analysis: The source text employs an oxymoron to give expression to a close rapport between the two main characters. In effect, Tokyo's rain cannot wet people in Paris. However, the composer conveys to listeners a tacit understanding between the two characters, and they may have the same routine even at a different time and place. Here, the translator deliberately omits the noun "day" to be in tune with rhymes and melodies of its front and after lines.

\section{Example 4}

Source Text: 下个路口再见吧

Translated Text: (At) Next junction (we) get together

Analysis: Here, the translator omits the preposition "at" and the subject "we" to closely match the source text on the one hand and keep its rhythm and melody on the other. Although it doesn't bring about mix-understandings, the translator might as well swap "next junction" with "get together" to make it an imperative sentence as "Get together next junction", thus overwhelming the emotional effect.

\subsubsection{Amplification}

Amplification is a translation technique opposite to omission. It is also called addition, meaning supplying necessary or omitted words in the translation based on an accurate comprehension of the original (Li \& Duan, 2016: p. 40) [8].

\section{Example 5}

Source Text: 你那边飞机碰巧也落地

Translated Text: Your plane also happened to arrive in

Analysis: Here, the preposition "in" is redundant for the verb "arrive" is intransitive. However, the verb "arrive" has to be followed by the preposition "in" 
and "at" in such circumstances as "arrive in a city or country" or "arrive at a specific place". Hence, "in" is unnecessary here, but still needs to be followed for rhyme and melody's sake.

\subsubsection{Conversion}

Conversion means that the part of speech, voice, and sentence components of the source text are converted to cater to the expression ways and habits of the target language. In terms of the part of speech, nouns sometimes can be adjusted to verbs or adjectives, while verbs can be modified to adjectives, adverbs, nouns, or prepositions (Ye, 2020: p. 26) [10].

\section{Example 6}

Source Text: 小小时差 Di Di Da

Translated Text: Little slack time Di Di Da

Analysis: The translator coverts the noun “时差” into an adjectival phrase "slack time", making the melodic sound vivid and vigorous. A slack period is one in which there is not much work or activity [11]. Here, the adjective is shifted to describe the time difference in a playful way. So this rendering can be regarded as delicate handling.

\subsection{Coherence Rule}

What the translator can do, and should do, is produce a text that is at least likely to be meaningful to target-culture receivers. In Vermeer's terms, the target text should conform to the standard of "intratextual coherence". Moreover, the coherence rule also specifies that a translation should be acceptable in a sense that it is coherent with the receivers' situation (Nord, 2018: p. 31) [6]. In other words, the translated text should be understandable and acceptable in receivers' communicative situation and culture.

\subsubsection{Adaption}

Sometimes literal translation makes readers feel confused because of the cultural differences. In comparison, adaptation can make the translation concise and easy for readers to read. This method is also called domestication (Li \& Duan, 2016: p. 40) [8].

In See the Next Intersection, the translator adopts this method every time literal translation may arouse confusion.

\section{Example 7}

Source Text: 711 暖杯巧克力

Translated Text: Seven-eleven, Cappuccino is great

Analysis: “巧克力” in the source text rhymes with the final syllable of “时机” and “冬季” in its front lines. However, the translator may consider the target listeners' customs and habits and alter the translation of “巧克力 chocolate” to "Cappuccino" correspondingly, making it coherent and familiar. As Cappuccino is a typically Western-style beverage, this adaption accommodates the target listeners' language and culture. 
Still, there is a little flaw in the translated text. The official name of the convenience store is "7-Eleven" instead of "Seven-eleven". 7-Eleven is a leader in the convenience retailing with over 67,000 stores operating in 21 countries and regions globally. The store name is created in 1946 and is now a hallmark of 7-Eleven's "around-the-clock" operating mode [12]. Hence, apart from concentrating on coherence, anadequate translation also requires translators' scrupulous attention to detail, such as the correct spelling of trademarks.

\section{Example 8}

Source Text: 当半个地球外还有个你

Translated Text: When I ran into you dramatically

Analysis: The translated text is a specific adaption of the source text. The translator does not merely render it as "We are half a world away" because it may confuse target listeners. Nevertheless, by adaption, she makes the translation more coherent and the emotional effect more romantic.

\section{Example 9}

\section{Source Text: 忙碌会议你头脑转不停}

Translated Text: You are always busy, like a spinning top

Analysis: The translated text applies a simile, comparing the character's busy day to a "spinning top", which is a lively description and hence a successful adaption as well. However, the source text is an exaggeration, conveying to listeners that the character is engaged in meeting all day long. Thus, although the adaption makes the translation concise and easy to read, the translated text does not deliver the full message of the source text, for the meaning of 会议 is missing during the adaption, minor though.

\section{Example 10}

Source Text: 我街头散步偷偷喘口气

Translated Text: Taking a walk, just to relax my soul

Analysis: The translator also fine-tunes the meaning of the source text “喘口 气” as "just to relax my soul" to make it more coherent and understandable to the target listeners. This adaption is appropriate for its catering to the target listeners' habits and tastes.

\subsubsection{Amplification \\ Example 11}

Source Text: 当相遇还没到对的时机

Translated Text: But it is not the right time when we met

\section{Example 12}

Source Text: 我偏爱弗朗明哥的热情

Translated Text: I prefer flamenco's passion, can't you see?

\section{Example 13}

Source Text: 深呼吸 你会在哪里

Translated Text: Taking a breath, where are you? I wanna know!

Analysis: In Example 11, the conjunction word "but" is added for coherence's purpose. The amplification makes the translated text more readable and accept- 
able by the target listeners. Furthermore, in a similar vein, the translator employs amplification in Example 12 and Example 13, adding "can't you see" and "I wanna know!" to generate coherence and avoid confusion.

\subsection{Fidelity Rule}

Since a translation is an offer of information about a source text, it is expected to bear some relationship with the corresponding source one. Vermeer calls this relationship "intertextual coherence" or "fidelity". This is postulated as a further principle, referred to as the "fidelity rule". This may be a form expected in literal translation (Nord, 2018: p. 31) [6].

Example 14

Source Text: 夏天一去 又是冬季

Translated Text: Summer has gone, winter has come

Example 15

Source Text: 秒针转动 Di Di Da

Translated Text: Sweep-second's ticking Di Di Da

Example 16

Source Text: 平行的画 Di Di Da

Translated Text: Parallel lines Di Di Da

Example 17

Source Text: 几时交叉 Di Di Da

Translated Text: Maybe cross one-time Di Di Da

Example 18

Source Text: 伦敦叹息 倾听悉尼

Translated Text: London will sigh, hear Sydney

Example 19

Source Text: 同时期就像在一起

Translated Text: The same time, we seem to be together

Analysis: All the above examples can be regarded as a maximally faithful imitation of the source text. Here, the adoption of literal translation is meaningful and can arouse empathy with the target listeners. Moreover, most literal translation here still keeps the original flavor. Still, in Example 18, to comply with the fidelity rule, the translator renders the sentence literally, but it may sound somewhat in-comprehensible.

\section{Conclusion}

Under the Skopos theory, fidelity is considered subordinate to coherence, and both are subordinate to the Skopos rule. Considering that, the translator adopts such translation techniques as omission, amplification, conversion, adaption, and literal translation to match words and music, thus achieving the purpose of singability in lyrics translation. Based on the Skopos theory, the translator preserves the original flavor of the song and reinforces its emotional effect in no small measure. However, to meet the end of integrating the verbal component 
into its rhythm and melody, a few grammar mistakes appear. Given that, this paper concludes it is of paramount importance to weigh up the three rules well. Besides, this paper offers some enlightenment about rendering excellent lyrics translation, while not making any rule sacrificed readily in the meantime. Hence, the song lyrics translation is a demanding task, which requires translators' consummate translating skills and their full knowledge of the source and target languages and culture.

\section{Acknowledgements}

I would like to express my heartfelt gratitude to my friends for their enlightenment throughout this study. I am also indebted to my family members, who have never failed to support my graduate study.

\section{Conflicts of Interest}

The author declares no conflicts of interest regarding the publication of this paper.

\section{References}

[1] Li Yuchun's Biography. https://www.businessoffashion.com/community/people/li-yuchun

[2] 下个, 路口，见(See the Next Intersection). https://baike.baidu.com/item/下个, 路口, 见/10161000?fromtitle=下个路口见 \&fromid $=9515298$

[3] 第六大街音乐工作室(Ave.6 Music Studio). https://baike.baidu.com/item/第六大街音乐工作室/9080800

[4] Chinese-English Song Lyrics of See the Next Intersection. https://y.qq.com/n/yqq/song/000gnVCU3OrVTq.html?ADTAG=h5_playsong\&no redirect $=1$

[5] Munday, J. (2016) Introducing Translation Studies Theories and Applications. 4th Edition, Routledge, New York. https://doi.org/10.4324/9781315691862

[6] Nord, C. (2018) Translating as a Purposeful Activity: Functionalist Approaches Explained by Christiane Nord. Routledge, New York.

[7] Reiß, K. and Vermeer, J.H. (2014) Towards a General Theory of Translational Action Skopos Theory Explained. Routledge, New York.

https://doi.org/10.4324/9781315759715

[8] Li, H.Y. and Duan, H.L. (2016) Analysis of the Translation Strategies of Ku Hungming's English Version of Zhongyong from the Perspective of the Skopos Theory. Cross-Cultural Communication, 12, 36-42. http://www.cscanada.net/index.php/ccc/article/view/8968

[9] WH-Words-Easy Learning Grammar. https:/grammar.collinsdictionary.com/easy-learning/wh-words

[10] Ye, L.X. (2020) A Report on the Translation of Records of Streets and Alleys in Chengdu (Excerpt) from the Perspective of Skopos Theory. M.A. Thesis, Sichuan Normal University, Chengdu.

[11] Definition of "Slack". https://www.collinsdictionary.com/dictionary/english/slack

[12] About 7-Eleven. https://www.7-eleven.com.hk/en/about/about-us 


\section{Appendix}

\section{《下个, 路口, 见》}

See the Next Intersection

刚下的地铁还不算拥挤

The subway is not really so crowded

你那边飞机碰巧也落地

Your plane also happened to arrive in

东京下雨 淋湿巴黎

Tokyo's rainy Paris rainy

收音机 你听几点几

Radio which channel you are listening

当半个地球外还有个你

When I ran into you dramatically

当相遇还没到对的时机

But it is not the right time when we met

夏天一去 又是冬季

Summer has gone winter has come

7-11 暖杯巧克力

Seven eleven Cappuccino is great

秒针转动 $\mathrm{Di} \mathrm{Di} \mathrm{Da}$

Sweep second's ticking Di Di Da

小小时差 Di Di Da

Little slack time Di Di Da

我早茶月光酒在你头发

Sprinkle the silver moon dust on your hair

平行的画 Di Di Da

Parallel lines Di Di Da

几时交叉 Di Di Da

Maybe cross one-time Di Di Da

下个路口再见吧

Next junction get together

忙碌会议你头脑转不停

You are always busy like a spinning top

我街头散步偷偷喘口气

Taking a walk just to relax my soul

伦敦叹息 倾听悉尼

London will sigh hear Sydney

同时期 就像在一起

The same time we seem to be together

我偏爱弗朗明哥的热情

I prefer flamenco's passion can't you see

你倾心维也纳古典钢琴

Your love is the classical piano of Vienna 
不曾相遇 未曾熟悉

We never meet unfamiliar

深呼吸 你会在哪里

Taking a breath where are you I wanna know 秒针转动 Di Di Da

Sweep second's ticking Di Di Da

小小时差 Di Di Da

Little slack time Di Di Da

我早茶月光酒在你头发

Sprinkle the silver moon dust on your hair 平行的画 Di Di Da

Parallel lines Di Di Da

几时交叉 Di Di Da

Maybe cross one-time Di Di Da

下个路口再见吧

Next junction get together

秒针转动 Di Di Da

Sweep second's ticking Di Di Da

小小时差 Di Di Da

Little slack time Di Di Da

我早茶月光酒在你头发

Sprinkle the silver moon dust on your hair 平行的画 Di Di Da

Parallel lines Di Di Da

几时交叉 Di Di Da

Maybe cross one-time Di Di Da

下个路口再见吧

Next junction get together 